\title{
Determinants of Employee Motivation - A Case Study of Afroze Textile Industries Limited, Karachi, Pakistan
}

\author{
Ghulam Muhammad ${ }^{1}$, Ubedullah Memon ${ }^{2}$ \\ '(Manager Human Resource, Mohammad Ali Jinnah University, Karachi, Pakistan) \\ ${ }_{2}^{2}$ (Lecturer of Business Administration, Mohammad Ali Jinnah University, Karachi, Pakistan)
}

\begin{abstract}
The purpose of this case study is to explore the employees' motivational practices in the Afroze Textile Industries, Karachi, Pakistan. This case study consists of primary and secondary sources of data via structured interviews, questionnaires, research articles, books and reports. In this research, convenient sampling style has been adopted with sample size of 50 respondents from middle and top level of employees. The result shows that the employees of the Afroze Textile Industries are not satisfied with motivational practices adopted by the company. More than 70\% employees think that only financial rewards are the main source of motivation. Just $10 \%$ employees are satisfied with the current performance appraisal system and they have fear of job security. Majority of employees are not involved in the decision making process. The finding also explores that more than $90 \%$ employees are happy with their co-workers' behavior and $80 \%$ are satisfied with health and safety measures adopted by the management which is a good sign. This case study will help the management of the Afroze Textile Industries to know the motivation level of their employees and best motivational practices thinking by the employees to get the maximum output. For future research, it is recommended to increase the sample size and include other textile companies for better findings.
\end{abstract}

Key Words: Motivation, Financial Rewards, Performance Appraisal, Job Security, Health and Safety.

\section{Textile Industry In Pakistan}

Pakistan is the fourth cotton producer of the world. Pakistani textile industry has a bright future as demand is increasing in the world market. Pakistani textile products are contributing more than 60 percent of the total export of the country and about $8.5 \%$ to the GDP of Pakistan. It generates $38 \%$ employment of the workforce of the country. Pakistan is also facing tough competition of textile products in the world market. Therefore, it is very important to pay attention on the motivation of human resource working in the textile industry for producing better quality and maximum output to compete the world market.

\section{The Afroze Textile Industries}

The Afroze Textile Industries was established in 1973 as a towel manufacturer company. Due to quality and reliability of the products, the company has earned reputation in national and international markets, that encouraged the management to establish new process integrated unit in 2001. The Afroze Textile is one of the premier names in the textile industry with the following products:

- Knitted Hosiery

- Woven Fabric

- Terry Towels

Being the market leader of home textile products, the company is trying to provide a better workplace environment to its employees. The Afroze Textile Industries has the following objectives to achieve:

- Maximization of profit by reducing cost

- Enhancing innovations through job satisfaction and employee career development opportunities

- Contribute in the growth of national economy

The management of the Afroze Textile Industries also focuses on the employees' safety and health by providing them tools for safety, healthy environment and safety training. 
Determinants of Employee Motivation - A Case Study of Afroze Textile Industries Limited, Karachi,

\section{Introduction}

Motivation in simple terms may be understood as the set of forces that cause people to behave in different positive ways. Productivity and quality of work depends on the motivation level of workforce working in the organization. Productive and quality oriented employees are usually highly motivated. Understanding the needs of employees and motivating them is not an easy task in the frequent changing environment. Employees have different needs and expectations when they join organizations. HR experts are trying to find out the different ways for motivating the employees but still they are not clear. Management mostly focuses on the human capital that plays a vital role in the organizational effectiveness compared with financial capital. People are more important than finance in modern times to get competitive advantage. The old organizations' culture no longer exists in the recent world of globalization. It is the need to improve the earlier period issues carefully. As the change have been seen in the culture of today's organizations, it is more essential for the companies to meet employees' need and introduce new benefits, financial rewards and competitive salary to motivate employees. Strong relationship between employees and organization is a tool for achieving the needs of changing work environment for both the parties. The role of top management is crucial to make strong bond with employees. The management encourages its best performing employees by giving them promotions and increase investment for their development. Employees prefer to join organizations where they succeed and get more promotional opportunities on the basis of their performance. Employees' participation in decision making and positive behavior with co-workers also increases their motivational level. Most empirical findings suggest that job security decreases employees' efforts.

\section{Purpose Of The Research}

Motivational practices in the textile sector of Karachi are the growing one. This research has been conducted to find out the motivational level of employees in the Afroze Textile, Karachi. Pakistan. In this research, efforts have been made to assist and guide the management of the Afroze Textile, Karachi and to provide viable solution on the subject matter of employees' motivation so that they can be able to develop their workforce in accordance with future requirement of textile sector. Findings of this research will definitely guide to increase the efficiency of employees and organization. Moreover, this research will enable employees to participate and strive for the betterment of organization.

\section{Literature Review}

Motivation in its original spirit can be defined as a mental process that gives purposeful behavior and direction [1]. Motivation as an internal force helps to fulfill an unsatisfied need by generating will and power to achieve. It is extensively regarded as a route to internal satisfaction and key to success [2]. Motivation is a tendency to behave in a methodical way to achieve the desired objective. It is a force which is always moving to do something for the accomplishment of your targets [3].

Human resource aspect of management postulates that it is people who make a business succeed or fail. It is the organization's chief responsibility to motivate their workforce so that they will assure success. Moreover, human capital has the potential to generate novel ideas to facilitate the strategic goal of organization. Organizations can obtain fruitful results by stimulating creativity among their employees; desire to succeed and to achieve self-fulfillment through their work [4].

In the contemporary world, organizations are visualizing their employees as the primary source of competitive advantage. Henceforth, the way employees are treated by the organization ultimately decides whether an organization will sustain and grow in the near future or not. This is an accurate assessment of the human capital in the organizations, which eventually decides the destiny of any organization [5].

In the general sense, reward programs are derived from the overall compensation strategies, which are defined to assist in developing pay system and enhancing integration mechanism. Through this mechanism, the efforts of various sub-units or individuals are directed towards the achievement of an organization's strategic objectives [6].

In operational sense, motivation is defined as the inner force that drives individuals to achieve personal and organizational goals. The main obstacle for managers is to get hold on how to motivate employees. Although it is very much difficult to motivate employees at all levels, but before doing so, it is very essential to know about the prerequisites that keep employees motivated [7].

In the dynamic organic culture, intrinsic and extrinsic rewards are good sources of motivation. Intrinsic rewards create internal sense of satisfaction among the employees while 
extrinsic rewards cover the financial aspect. Reward and recognition programs come within the discussion on extrinsically motivated behavior that occurs when an activity is rewarded by incentives not inherent in the task [8].

Multiple businesses are using pay, promotion, bonuses and other motivational tools to encourage high level of performance among their employees. Moreover, it can be said that these tools are providing twofold benefits. Firstly, it is very essential for the retention of competent and stable workforce and secondly, it is a useful technique to maintain and upgrade a sense of satisfaction among the skilled employees [9].

\section{Research Methodology}

In Pakistan, textile sector could not achieve a great distinction in applying motivational tools and techniques. As a result, satisfaction level of employees in the textile sector of Pakistan is decreasing day by day. This research focuses on the motivational tools and techniques which are being applied by the Afroze Textile, Karachi, Pakistan, through secondary and primary sources i.e. structured interviews, questionnaires, books, the Afroze Textile reports, magazines and articles. This research encompasses 50 respondents through one to one interview technique of research. The respondents are the top and middle level employees of the Afroze Textile in the region of Karachi, Pakistan.

\section{Research Limitations}

This research is conducted only in the Afroze Textile, Karachi, Pakistan, henceforth the findings of this research cannot be applied in all other sectors of Karachi, Pakistan. This research also faced some time constraints; there was a limited time to conduct this research and respondents were not free enough to respond properly. This research considered top and middle level employees of the Afroze Textile, Karachi, who are a very small percentage of overall workforce.

Table 1.1 Gender

\section{Results And Discussions}

\begin{tabular}{|l|c|c|}
\hline Gender & Respondents & Percentage \\
\hline Male & 38 & $76 \%$ \\
\hline Female & 12 & $24 \%$ \\
\hline Total & 50 & $100 \%$ \\
\hline
\end{tabular}

This table clearly shows that 38 respondents are male, who are $76 \%$, and 12 are female respondents, who are $24 \%$.

Table 1.2 indicates that in the Afroze Textile, Karachi, the majority of employees who are working at top and middle levels are of 23-32 years old. It means that there are large number of employees who are young, energetic and have fresh blood in their veins. This is a positive sign and could be used for the betterment of the Afroze Textile.

Table 1.3 Experiences

Table 1.2 Age

\begin{tabular}{|c|c|c|}
\hline Years & Respondents & Percentage \\
\hline $18-22$ & 8 & $16 \%$ \\
\hline $23-27$ & 12 & $24 \%$ \\
\hline $28-32$ & 20 & $40 \%$ \\
\hline $33-37$ & 8 & $16 \%$ \\
\hline $38-42$ & 2 & $04 \%$ \\
\hline Total & 50 & $100 \%$ \\
\hline
\end{tabular}

\begin{tabular}{|l|c|c|}
\hline Years & Respondents & Percentage \\
\hline $0-3$ & 12 & $24 \%$ \\
\hline $04-06$ & 22 & $44 \%$ \\
\hline $07-09$ & 12 & $24 \%$ \\
\hline $10-12$ & 4 & $08 \%$ \\
\hline Total & 50 & $100 \%$ \\
\hline
\end{tabular}

The results in Table 1.3 clearly depicts that $44 \%$ of the respondents are working in the Afroze Textile, Karachi for 04-06 years. It means that there are large number of employees who are holding middle management level experience to manage day to day affairs of the organization.

\subsection{Motivational Programs}

Employees of the Afroze Textile are thinking that motivational programs are playing very important role for the retention of competent and stable workforce. Most of the employees have the opinion that management is not using good motivational tools and techniques which is an alarming situation. $70 \%$ of the respondents agree that only financial rewards are important for the motivation of employees, and 30\% respondents are of the opinion that financial and non-financial rewards both are necessary for the motivation of employees. 


\subsection{Performance Appraisal and Promotions}

In the Afroze Textile, only $45 \%$ respondents agreed that performance management system is very essential for the motivation of employees. It is very much important to note that just $10 \%$ employees are satisfied with the current performance management system, while $90 \%$ remained neutral due to their personal limitations. 55\% respondents remained neutral on the promotional opportunities given to them in the organization, and $45 \%$ respondents disagreed with the current promotional systems.

\subsection{Employees Participation in the Decision Making}

Majority of employees said that they have no participation or occasional participation in decision making. Only few respondents said that management involves them in the major decision making process, including decisions related to their jobs.

\subsection{Relationship with the Co-workers}

Good relationship management with the co-workers is a big challenge in the corporate world. It is a factor which motivates employees to stay in the organization for a longer period of time. Henceforth, large number of employees are giving priority to this factor over other subjects. 95\% respondents in the Afroze Textile, Karachi have good relationship with their co-workers and $5 \%$ remained neutral.

\subsection{Health, Safety and Job Security}

$80 \%$ respondents are satisfied with the health and safety measures adopted by the Afroze Textile, Karachi. Very few employees feel job security. The management of the company needs to pay attention on employees' job security, as employees are not satisfied with the retention policy.

\section{Conclusion}

The research concludes that motivation in any form is very essential for the employees' productivity. It is an important tool for the retention of competent and stable workforce. This research also concludes that the management is not really serious to motivate their employees. It is an alarming situation and requires serious efforts from the management side to bring positive change. Besides that, significant portion of respondents are not satisfied with their current performance appraisal system which creates frustration and dissatisfaction among employees.

In addition, large numbers of employees are deprived from participation in the major decision making process which increases gap between management and employees. Moreover, respondents also showed disappointment towards financial and non financial rewards and job security.

Employees are satisfied having the relationship with their co-workers and measures adopted for their health and safety by the management.

\section{References}

[1] Kreitner, R. Management (6th ed) (Boston: Houghton Mifflin Company, 1995).

[2] Higgins, J. M. The management challenges (2nd ed.) (New York: Macmillan1994).

[3] Buford, J. A., Bedeian, A.G., \& Lindner, J. R. Management in extension (3rd ed) Columbus, Ohio:Ohio State University, 1995.

[4] Carnegie, Harvard Analytical Framework for Human Resource Management, 1975.

[5] Lawler, E. E. Reward practices and performance management system effectiveness. Organizational Dynamics, 32(4), 2003. 396-404.

[6] Gomez-Mejia, L. and Balkin, D. "The Determinants of Faculty Pay: An Agency Theory Perspective," Academy of Management Journal, 35, 1992, 921-955.

[7] Bruce and James S. Pepitone McGraw-Hill, 1999, 176 pages.

[8] Deci, E. Effects of externally mediated rewards on intrinsic motivation. Journal of Personality and Social Psychology, 18, 1971, 105-115.

[9] Cameron, J., \& Pierce, W. D. Reinforcement, reward, and intrinsic motivation: A meta-analysis. Review of Educational Research, 64, 1977-1978, 363-423. 